\title{
Long term treatment of myasthenia gravis with azathioprine
}

\author{
V. Fonseca and C.W.H. Havard \\ Royal Free Hospital, Pond Street, London NW3 2QG, UK.
}

Summary: Twenty-seven patients with myasthenia gravis have been treated with azathioprine in conjunction with pyridostigmine and prednisolone for a total of 138 patient years. Side effects necessitated discontinuation of treatment in only four patients. Treatment with azathioprine was associated with marked clinical improvement in all the remaining 23 patients, resulting in reduction in the dose of pyridostigmine and prednisolone. The number of hospital admissions as well as the number of episodes of respiratory failure were markedly reduced.

\section{Introduction}

Although azathioprine has been used in the treatment of myasthenia gravis for more than 15 years, ${ }^{1}$ its place remains controversial. ${ }^{2,3}$ We have been using azathioprine as a means of inducing remission in myasthenia gravis for a period of 10 years. It seemed an appropriate moment to analyse retrospectively the case notes of the 27 patients with myasthenia gravis who had been treated with this form of immunosuppression.

\section{Patients and methods}

Twenty-seven patients were treated with azathioprine. Patients with thymic tumours were excluded as the course of the disease is less predictable in such cases.

Myasthenia gravis was diagnosed on the basis of typical clinical features and a positive edrophonium test. In addition electromyographic studies were undertaken in 25 patients and confirmed fatiguability; acetylcholine receptor antibodies, as determined by the method of Lindstrom et al. ${ }^{4}$ were positive in 26 patients. The only patient in whom antibodies could not be detected responded to plasma exchange and gave birth to a child with transient neonatal myasthenia and so it would seem that a circulating factor was responsible. ${ }^{5,6}$

The clinical features of the patients at the time of starting azathioprine are summarized in Table I. An attempt was made to optimize pyridostigmine therapy for at least 3 months prior to starting azathioprine. Twenty patients were being treated

Correspondence: V. Fonseca, M.D., M.R.C.P.

Accepted: 5 September 1989
Table I Clinical characteristics of 27 patients with myasthenia started on azathioprine

\begin{tabular}{|c|c|}
\hline Age (years) & 42 \\
\hline Median (range) & $(26-64)$ \\
\hline Females & 19 \\
\hline Median duration of myasthenia (years) & 9 \\
\hline (range) & $(0.5-22)$ \\
\hline Previous thymectomy & 21 \\
\hline $\begin{array}{l}\text { Median duration since thymectomy (years) } \\
\text { (range) }\end{array}$ & $\begin{array}{l}3 \\
(0.5-15)\end{array}$ \\
\hline $\begin{array}{l}\text { Average dose of pyridostigmine (mg/day) } \\
\text { (range) }\end{array}$ & $\begin{array}{l}600 \\
(180-1200)\end{array}$ \\
\hline Number on corticosteroids & 20 \\
\hline $\begin{array}{l}\text { Steroid dose }\left(\mathrm{mg} / \text { day of prednisolone }{ }^{*}\right) \\
\text { (range) }\end{array}$ & $\begin{array}{l}15 \\
(5-20)\end{array}$ \\
\hline \multicolumn{2}{|l|}{ Number of hospital admissions in } \\
\hline previous year 1 & 4 \\
\hline 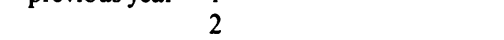 & 5 \\
\hline 3 or more & 11 \\
\hline Number with difficulty breathing/swallowing & 15 \\
\hline \multicolumn{2}{|l|}{ Number who required mechanical } \\
\hline ventilation once & 7 \\
\hline more than once & 6 \\
\hline $\begin{array}{l}\text { Number previously treated with plasma } \\
\text { exchange }\end{array}$ & 6 \\
\hline
\end{tabular}

*Usually given as twice this dose on alternative days.

with prednisolone and in none of these patients had the prednisolone been commenced in the 3 months prior to starting azathioprine.

Clinical grading of the patients was done by a modification of criteria previously described: ${ }^{7}$ Grade 1a: no weakness, pyridostigmine not required; $1 \mathrm{~b}$ : no weakness but pyridostigmine necessary; Grade 2: mild weakness not limiting the patients life-style; Grade 3: moderate weakness affecting the patient's life-style and ability to work. No weakness of respiratory muscles, no weakness 
of swallowing or chewing; Grade 4: severe weakness; difficulty in breathing, swallowing, chewing and speech.

\section{Results}

Twenty seven patients received azathioprine. In four of these patients treatment was discontinued because of side effects; one patient developed jaundice and another abnormal liver function tests within one month of starting the drug. One of them was subsequently treated with cyclophosphamide $50 \mathrm{mg}$ daily for 3 years with a good response and the other was maintained on corticosteroids. The third patient developed portal hypertension secondary to nodular regenerative hyperplasia of the liver after 3 years' treatment. Azathioprine was discontinued and his myasthenia deteriorated from Grade 2 to Grade 3. The fourth patient was treated with azathioprine for 4 years with a good response (Grade 4 to Grade 2) but discontinued treatment because of recurrent upper respiratory tract infections. On stopping treatment her myasthenia deteriorated (Grade 3), and her upper respiratory tract infections were unchanged.

The remaining 23 patients were available for further analysis. The median duration of treatment in these patients was 7 years (range 1-10 years). Treatment was given for a total of 138 patient years. The median dose of azathioprine was $100 \mathrm{mg}$ daily (range $75-200 \mathrm{mg} ; 1.5-3 \mathrm{mg} / \mathrm{kg}$ body weight).

Clinical improvement was usually observed after 6 months. It has been possible to electively discontinue azathioprine because of a full clinical remission (Grade 1a) in two patients (one after 5 years and the other after 7 years).

The effects of azathioprine are summarized in Table II. There has been a marked clinical improve- ment in all patients resulting in reduction in the dose of pyridostigmine and corticosteroids as well as in the number of hospital admissions. Only two patients suffered further episodes of respiratory failure requiring assisted ventilation, both within one year of commencing azathioprine. Both have subsequently improved and are currently in Grade $1 b$ and Grade 2. Apart from those who discontinued azathioprine because of side effects three patients (all in Grade 1a) discontinued treatment on advice (two after 5 years and one after 7 years) and symptoms have not recurred over the subsequent two years.

No patient has developed a white cell count of less than $2.5 \times 10^{9} / 1$ and none has reported recurrent infection apart from the single patient described above. We have not observed a single episode of infection by organisms associated with immunocompromised patients. Macrocytosis was seen in all patients. In 1977 patients with myasthenia gravis occupied beds in our intensive therapy unit for 1121.5 patient days. In 1987 only one patient required assisted ventilation. This reduction in respiratory failure was seen despite no reduction in the number of patients attending our clinic.

One patient reported 3 months amenorrhoea whilst on azathioprine and was found to be pregnant. Azathioprine was continued through the pregnancy which resulted in a normal child, delivered at term.

\section{Discussion}

Our data demonstrate that azathioprine is effective in the treatment of myasthenia gravis. Furthermore, the incidence of side effects is low, allowing long-term therapy to maintain remission in the majority of patients.

Table II Effect of azathioprine in 23 patients with myasthenia gravis

\begin{tabular}{llll}
\hline & Pre-azathioprine & $\begin{array}{c}\text { Post-azathioprine } \\
\text { (current status) }\end{array}$ \\
\hline Clinical grade & la & 0 & 4 \\
& $1 \mathrm{~b}$ & 0 & 11 \\
& 2 & 0 & 8 \\
& 3 & 10 & 0 \\
$\begin{array}{l}\text { Hospital admission in } \\
\text { last year }\end{array}$ & 13 & 0 \\
$\begin{array}{l}\text { Median (range) dose of } \\
\text { pyridostigmine } \\
\text { mg/day }\end{array}$ & 40 & 1 \\
$\begin{array}{l}\text { Median (range) dose of } \\
\text { prednisolone } \\
\text { mg/day }\end{array}$ & 600 & \\
\end{tabular}


As myasthenia gravis is an immunological disorder it would seem rational to use an immunosuppressive form of treatment to eliminate the acetylcholine receptor antibody. There have been several reports on the efficacy of immunological treatment including thymectomy, ${ }^{7}$ corticosteroids, $^{8}$ azathioprine $^{1}$ and plasma exchange. ${ }^{9}$ We did not feel that a controlled trial of azathioprine was ethically justified as it would require denying a group of patients a form of treatment that had been shown to be effective. ${ }^{1}$ It is therefore not surprising that no placebo controlled trials of azathioprine have been reported. Tindall $e t$ al. reported the first placebo controlled trial of immunosuppressive therapy in myasthenia gravis using cyclosporin. ${ }^{10}$ In this trial however patients treated with other immunosuppressive drugs were excluded and nephrotoxicity of cyclosporin was a major problem. Furthermore, patients who had undergone thymectomy were excluded. As most young patients with myasthenia gravis are treated by thymectomy this resulted in the patients entering the trial being in an older age group with an average age of 65 years, a group known to be responsive to immunosuppressive therapy.

Our study, albeit uncontrolled, confirms the findings of Mertens et al. of the efficacy and long-term safety of azathioprine. ${ }^{11}$ Although no direct comparative trial between azathioprine and cyclosporin has been carried out it appears that azathioprine is the safer drug for long-term therapy. The use of azathioprine has resulted in considerable change in our clinical practice. Not only has the admission to hospital declined but there has been a marked reduction in the number of patients requiring assisted ventilation thus reducing morbidity considerably.

Prednisolone is accepted as being of benefit in myasthenia and a remission rate of $80 \%$ has been reported. ${ }^{8}$ Long-term treatment with prednisolone, however, has been associated with considerable side effects. Twenty of our patients were on prednisolone at the time of starting azathioprine and most were noted to have cushingoid features. Addition of azathioprine resulted in control of symptoms with a significantly smaller dose of prednisolone resulting in less side effects. Plasma exchange has been shown to be beneficial in patients with severe weakness. ${ }^{9}$ The benefit, however, is short-lived. We have not observed a severe relapse of symptoms in patients who commenced azathioprine at the time of plasma exchange. Twenty-one of our patients had previously undergone thymectomy a median period of 3 years prior to starting azathioprine. Some of the beneficial effect seen could be therefore due to the thymectomy. However, it may take up to 10 years for remission following thymectomy and azathioprine may be of benefit in severely disabled patients until a thymectomy remission is obtained. Five of our patients had had a thymectomy 10 years earlier without apparent benefit and improved dramatically over 6 months after commencing azathioprine. Whether this benefit is due to azathioprine alone or a combined effect of azathioprine and thymectomy is not clear.

The low incidence of side effects of azathioprine in our patients is remarkable. Cholestatic jaundice is common but is usually seen soon after commencing treatment and is reversible. ${ }^{12}$ Portal hypertension due to nodular regenerative hyperplasia was seen in one of our patients after 4 years' treatment ${ }^{13}$ and has previously been described in patients taking azathioprine following kidney transplantation. ${ }^{14}$ Although one of our patients reported recurrent respiratory infections on azathioprine she remained infection-prone after stopping the drug. The rarity of serious infections despite up to 10 years use of a powerful immunosuppressive drug is encouraging. We have not observed any serious bone marrow toxicity in our patients. No patient developed leucopenia and the only abnormality consistently noted was a raised mean corpuscular volume. Our experience therefore differs from that of Hohlfeld et al. who reported a $36 \%$ incidence of side effects in patients with myasthenia gravis treated with azathioprine. ${ }^{15}$ These investigators, however, admit that this high incidence is probably an over-estimate as some of the side effects were clearly not related to azathioprine treatment and several were trivial, including minor reductions in the white cell count. Furthermore, some of the patients in their series were treated with much higher doses of azathioprine than we have found necessary.

We electively and successfully discontinued azathioprine in only two patients after 5 and 7 years treatment. In the four patients who stopped treatment because of side effects the myasthenia deteriorated. Michels et al. attempted stopping azathioprine after a shorter period of treatment with a high rate of relapse of symptoms and rise in auto-antibody titre. ${ }^{16}$ They have suggested that after withdrawal of azathioprine close follow up is essential and that a rise in titre of acetylcholine receptor antibodies is a useful indicator of impending relapse.

We conclude that azathioprine either alone or in conjunction with corticosteroids has a place in the management of myasthenia gravis, especially in patients in whom the response to thymectomy is poor or is delayed. Thymectomy, however, remains the initial treatment of choice for the young patient with myasthenia gravis. 


\section{References}

1. Mertens, H.G., Balzeriet, F. \& Leipert, M. The treatment of severe myasthenia gravis with immunosuppressive agents. Eur Neurol 1969, 2: 321-339.

2. Rowland, L.P. Controversies about the treatment of myasthenia gravis. J Neurol Neurosurg Psychiatry 1980, 43: 644-659.

3. Simpson, J.A. \& Thomaides, T. Treatment of myasthenia gravis. An audit. $Q J$ Med 1987, 64: 693-704.

4. Lindstrom, J.M., Seybold, M.E., Lennon, V.A., Whittingham, S. \& Duane, D.D. Antibody to acetylcholine receptor in myasthenia gravis. Neurology 1976, 26: 1054-1059.

5. Mier, A.H. \& Havard, C.W.H. Diaphragmatic myasthenia in mother and child. Postgrad Med J 1985, 61: 725-727.

6. Newsom Davis, J., Pinching, A.J., Vincent, A. \& Wilson, S.G. Function of circulating antibody to acetylcholine receptor in myasthenia gravis. Neurology 1978, 28: 266-272.

7. Scadding, G.K., Havard, C.W.H., Lange, M.J. \& Domb, I. The long term experience of thymectomy for myasthenia gravis. J Neurol Neurosurg Psychiatry 1985, 48: 401-406.

8. Pascuzzi, R.M., Coslett, H.B. \& Johns, T.R. Long term corticosteroid treatment of myasthenia gravis. Report of 116 patients. Ann Neurol 1984, 15: 291-298.

9. Newsom Davis, J., Vincent, A., Wilson, S.G. \& Ward, C.D. Long-term effects of repeated plasma exchange in myasthenia gravis. Lancet 1978, i: 464-468.
10. Tindall, R.S.A., Rollins, J.A., Phillips, J.T., Greenlee, R.G., Wells, L. \& Belendiuk, G. Preliminary results of a doubleblind, randomised, placebo-controlled trial of cyclosporine in myasthenia gravis. $N$ Engl J Med 1987, 316: 719-724.

11. Mertens, H.G., Herstel, G., Reuther, P. \& Ricker, K. Effect of immunosuppressive drugs (azathioprine). Ann N Y Acad Sci 1981, 377: 691-698.

12. Simon, N. \& Del Greco, F. Intrahepatic cholestasis due to azathioprine. Gastroenterology 1969, 57: 439-441.

13. Fonseca, V. \& Havard, C.W.H. Portal hypertension secondary to azathioprine in myasthenia gravis. Postgrad Med $J$ 1988, 64: 950-952.

14. Nataf, C., Feldmann, G., Leblec, D., Degott, C., Descamps, J.H., Rueff, B. \& Benhamou, J.P. Idiopathic portal hypertension (perisinusoidal fibrosis) after renal transplantation. Gut 1979, 20: 531-537.

15. Hohlfeld, R., Michels, M., Heininger, K., Bessinger, U. \& Toyka, K.V. Azathioprine toxicity during long-term immunosuppression of generalized myasthenia gravis. Neurology 1988, 38: 258-261.

16. Michels, M., Hohlfeld, R., Hartung, H.P., Heininger, K., Bessinger, U.A. Myasthenia gravis: discontinuation of longterm azathioprine. Ann Neurol 1988, 24: 798. 